\title{
Correlates of current suicide risk among Thai patients with bipolar I disorder: findings from the Thai Bipolar Disorder Registry
}

This article was published in the following Dove Press journal:

Neuropsychiatric Disease and Treatment

8 October 2013

Number of times this article has been viewed

\section{Sirijit Suttajit ${ }^{\prime}$ \\ Suchat Paholpak ${ }^{2}$ \\ Somrak Choovanicvong ${ }^{3}$ \\ Khanogwan Kittiwattanagul ${ }^{4}$ \\ Wetid Pratoomsri ${ }^{5}$ \\ Manit Srisurapanont ${ }^{\prime}$}

On behalf of the Thai

Bipolar Registry Group

'Department of Psychiatry, Chiang Mai University, Chiang Mai, ${ }^{2}$ Department of Psychiatry, Khon Kaen

University, Khon Kaen, ${ }^{3}$ Srithanya Hospital, Nonthaburi, ${ }^{4}$ Khon Kaen Rajanagarindra Psychiatric Hospital, Khon Kaen, ${ }^{5}$ Chachoengsao Hospital, Chachoengsao, Thailand
Correspondence: Manit Srisurapanont Department of Psychiatry, Faculty of Medicine, Chiang Mai University, II 0 Intavaroros Road, Sri Phum,

Muang, Chiang Mai 50200, Thailand

Tel +6653945422

Fax +6653945426

Email manit.s@cmu.ac.th
Background: The Thai Bipolar Disorder Registry was a prospective, multisite, naturalistic study conducted in 24 hospitals across Thailand. This study aimed to examine the correlates of current suicide risk in Thai patients with bipolar I disorder.

Methods: Participants were adult inpatients or outpatients with bipolar disorder, based on the Diagnosis and Statistical Manual of Mental Disorders, fourth edition. All were assessed by using the Mini International Neuropsychiatric Interview (MINI), version 5. The severity of current suicide risk was determined by using the total score of the MINI suicidality module. Mood symptoms were assessed by using the Young Mania Rating Scale and the Montgomery Asberg Depression Rating Scale.

Results: The data of 383 bipolar I disorder patients were included in the analyses. Of these, 363 (94.8\%) were outpatients. The mean (standard deviation) of the MINI suicide risk score was 1.88 (5.0). The demographic/clinical variables significantly associated with the MINI suicide risk scores included age, number of overall previous episodes, the Young Mania Rating Scale score, the Montgomery Asberg Depression Rating Scale scores, and the Clinical Global Impression Severity of Illness Scale for Bipolar Disorder mania score, depression score, and overall score. The variables affecting the differences of suicide risk scores between or among groups were type of first mood episode, a history of rapid cycling, anxiety disorders, and alcohol use disorders. The stepwise multiple linear regression model revealed that the Montgomery Asberg Depression Rating Scale score $(\beta=0.10)$, a history of rapid cycling $(\beta=6.63)$, anxiety disorders $(\beta=2.16)$, and alcohol use disorders $(\beta=2.65)$ were significantly correlated with the suicide risk score (all $P<0.01$ ).

Conclusion: A history of rapid cycling, severity of depressive episode, current anxiety disorders, and current alcohol use disorders correlate with current suicide risk among Thai bipolar I disorder patients. Further studies in larger sample sizes are warranted.

Keywords: Asian, bipolar disorder, correlates, risk, suicide, Thai

\section{Introduction}

Bipolar disorder (BD) is associated with marked premature death, with a mortality rate two to three times higher than the general population. ${ }^{1}$ Although this increased mortality is in part due to accidents, medical illnesses, and alcohol abuse, the greatest part of excessive death mainly results from suicide. ${ }^{2}$ BD patients are at higher risk of attempted and completed suicide than patients with other mental disorders. ${ }^{3-5}$ Researchers estimate that $21 \%-54 \%$ of BD individuals will attempt suicide at least once in their lifetime, and $10 \%-18 \%$ of them will have premature death. ${ }^{5,6}$

Previous suicide research in $\mathrm{BD}$ patients has highlighted a number of correlates and risk factors. These may include family history of suicide or mood disorders, 
early negative life events, previous suicide attempts, early in the illness course, early onset of illness, a long duration of untreated illness, rapid cycling, psychosocial stressors, comorbid Axis I and II disorders, serious medical illness, lack of medical treatment, lack of social or family support, extent of depressive symptoms, increasing severity of mood episodes, psychotic symptoms, atypical features, the presence of mixed affective states, and abuse of alcohol and drugs. ${ }^{7-9}$ While suicidal ideation and a history of attempted suicide are among the most important risks for suicide, ${ }^{10,11}$ only a few studies have taken into account both suicidal ideas and attempts in assessing the risk factors.

While suicidal behaviors may be different among ethnic groups, little is known about the suicide risk in Asian BD patients. A study carried out in the UK also found that suicide ideas were less common in South Asians (Indian, Pakistani, and Bangladeshi), as well as Black Caribbean and Black Africans, compared with White British. ${ }^{12}$ For those living in a community, Asians have a higher suicide rate, lower male-to-female suicide gender ratio, and higher elderly-togeneral-population suicide ratios than Caucasians. ${ }^{13}$ In addition, acute life stress (eg, family conflicts, job and financial security issues) plays a more important role than mental illness in causing suicidal behavior. Although there have been some studies of suicide risk in Asian BD patients, only one study has examined a comprehensive list of risk factors in 101 Taiwanese BD patients with attempted suicide. ${ }^{14}$ This study found that early age of onset, interpersonal problems, occupational problems, and a large number of episodes were predictors of suicide attempts. Interestingly, the risk factors of interpersonal and occupational problems found in this study were rarely found in Western studies. These results suggest that predictors of suicide attempts in Asian BD patients may differ from those of Westerners.

As suicidal behavior in patients with mood disorder is a "state dependent" phenomenon, ${ }^{15}$ it would be of interest to determine the correlates of current suicide risk in BD patients. Together with the aforementioned limitations of evidence in Asian BD patients, the authors proposed to examine the correlates of current suicide risk, taking into account suicidal ideation, suicidal plan, suicidal attempts, and a history of attempted suicide in Thai BD I patients.

\section{Methods}

The Thai Bipolar Disorder Registry, implemented in Thailand, was a prospective, national, multisite, naturalistic study conducted in 24 university, public mental, and public general hospitals. Its primary aim was to characterize the illness course in BD patients. Its details have been published in a recent article. ${ }^{16}$ This study did not involve any clinical management of the enrolled participants, and it was approved by the Institutional Review Board or Ethics Committee of each site. Prior to their participation, all participants gave written informed consent after the study details had been fully explained.

\section{Participants}

Participants were aged $\geq 18$ years old and were inpatient or outpatients with BD I or II. Those participating in other investigational studies and those with travel difficulty were excluded. They were prospectively enrolled from inpatients or outpatients receiving psychiatric treatment at the respective study sites.

\section{Assessment}

All participants were assessed at baseline (visit 1) and every 2 months ( \pm 1 month) for 12 months (visit 7). Data collected at baseline were demographic details, history of BD, psychiatric treatment, and physical comorbidity. Assessment at baseline and endpoint included current status of BD and health status. Measures used for evaluating the current status of BD were the Mini International Neuropsychiatric Interview (MINI), version $5,{ }^{17}$ the Young Mania Rating Scale (YMRS), ${ }^{18}$ the Montgomery Asberg Depression Rating Scale (MADRS), ${ }^{19}$ and the Clinical Global Impression Severity of Illness Scale for BD (CGI-BP-S). ${ }^{20}$ The health status was assessed by using Rand 36-Item Health Survey (SF-36). ${ }^{21,22}$ Patients with rapidcycling were defined as having four or more manic, mixed, or depressive episodes in the year prior to baseline assessment.

The MINI suicidality module was used to determine the current suicide risk. It consists of nine questions relevant to suicidal behavior. Each question asked for a yes/ no response. The questions (score for a positive response) were as follows: 1) intentional accident (zero points); 2) death wish (one point); 3) self-harm wish (two points); 4) suicide idea (six points); 5) suicide plan (eight points); 6) suicide plan with preparation (nine points); 7) deliberate injuring of oneself (four points); 8) suicide attempt in the past month (ten points); and 9) suicide attempt in lifetime (four points). Of note, as proposed by the developers, the positive response to the first question of intentional accident has no score. The suicide risk scores range from 0-52. Since all questions, except lifetime suicide attempt, are relevant to suicidal behavior during 1 month prior to assessment, the total score of this module therefore reflects the severity of current suicide risk. Although a history of attempted suicide 
is not a current condition, it is a risk factor highly ranked for suicide assessed by most psychiatrists. ${ }^{10,23}$ In developing a one-item questionnaire for assessing suicide risk, a history of attempted suicide was found to have high sensitivity $(0.80)$ and very high specificity (0.97) in differentiating between suicidal and nonsuicidal adult inpatients. ${ }^{10}$ In addition, it is the strongest and most robust predictor of suicide attempts and suicide completion in mentally ill and BD patients. ${ }^{5,7}$ As proposed by the developers of MINI and the aforementioned rationales, the item of previous attempted suicide of this MINI module was therefore included as a part of the current suicide risk.

Other MINI modules used in this registry included major depressive episode, (hypo)manic episode, panic disorder, agoraphobia, social phobia (social anxiety disorder), obsessive-compulsive disorder, alcohol abuse and dependence, non-alcohol psychoactive substance use disorders, and generalized anxiety disorder. Because only one module of MINI can elicit lifetime mental disorders (ie, panic disorder), only current mental disorders were taken into account.

\section{Statistical analysis}

Only baseline data were included in the analysis. Alcohol abuse and dependence were pooled as alcohol use disorders. Panic disorder, agoraphobia, social phobia (social anxiety disorder), obsessive-compulsive disorder, and generalized anxiety disorder were grouped as anxiety disorders. Because only 20 BD II patients were registered and might have a different pattern of suicidal behavior compared with BD I counterparts, ${ }^{24}$ only the data of BD I patients were included in the analysis.

Variables were expressed as mean (standard deviation [SD]) and number (\%). First, Pearson's correlation coefficients were calculated to determine the significant associations of continuous demographic/clinical variables and the suicide risk scores. For categorical variables, the differences of suicide risk scores between or among groups were examined using Student's $t$-test and one-way analysis of variance, respectively. Stepwise multiple linear regression analysis of the suicide risk score was applied to determine its significant predictors $(P<0.05) . R^{2}$ and adjusted $R^{2}$ were analyzed to evaluate the ratio of the sum of squares explained by a regression model. Coefficient values with $95 \%$ confidence intervals were used to quantify the strength of associations. The statistical significance for all tests was set at $P<0.05$. Statistical analyses were performed using the software package SPSS Statistics 17.0 (IBM Corporation, Armonk, NY, USA).

\section{Results}

The data of 383 BD I patients were included in this study. Of these, 233 (60.8\%) were female, and 363 (94.8\%) were outpatients. The mean (SD) of age and age of onset were 42.3 (12.2) and 31.3 (11.6) years old, respectively. Of 383 participants, 303 currently had no mood episode. Current mood episodes were as follows: manic $(n=31)$, major depressive $(n=25)$, hypomanic $(n=17)$, and mixed $(n=7)$. The mean (SD) of YMRS and MADRS scores were 3.8 (5.7) and 4.9 (6.6), respectively. Prevalence of nine suicidal behaviors were as follows: intentional accident (7.3\%), death wish (9.9\%), self-harm wish (3.7\%), suicide ideation (5.2\%), suicide plan (1.6\%), suicide plan with preparation $(0.8 \%)$, deliberate injuring of oneself $(1.3 \%)$, suicide attempt in the past month (2.1\%), and suicide attempt in lifetime (20.6\%). The mean (SD) of the MINI suicide risk score was 1.88 (5.0).

Tables 1 and 2 show the variables included in the univariate analyses. By using Pearson's correlation coefficient $r$, the continuous demographic/clinical variables significantly associated with the MINI suicide risk scores were age $(P=0.02)$, number of overall previous episodes $(P=0.02)$, the YMRS score $(P<0.01)$, the MADRS scores $(P<0.01)$, the CGIBP-S mania score $(P<0.01)$, the CGI-BP-S depression score $(P<0.01)$, and the CGI-BP-S overall score $(P<0.01)$ (Table 1). The variables affecting the differences of suicide risk scores between or among groups included type of first mood episode $(P<0.01)$, a history of rapid cycling $(P<0.01)$,

Table I Sociodemographic/clinical characteristics and their correlations with suicide risk among 383 Thai bipolar I disorder patients

\begin{tabular}{lll}
\hline $\begin{array}{l}\text { Sociodemographic/clinical } \\
\text { characteristics }\end{array}$ & Mean (SD) & $\begin{array}{l}\text { Significant } \\
\text { correlation }(\boldsymbol{r}, \boldsymbol{P})\end{array}$ \\
\hline Age (years) & $42.3(\mathrm{I} 2.2)$ & $-0.12,0.02$ \\
Age at onset (years) & $3 \mathrm{I} .3(\mathrm{II} .6)$ & $-0.10,0.05$ \\
Years of untreated illness & $4.2(6.9)$ & $-0.04,0.42$ \\
Number of all previous episodes & $4.9(5.0)$ & $0.13,0.02$ \\
Number of previous manic/ & $3.1(2.8)$ & $0.05,0.35$ \\
hypomanic episodes & & \\
Number of previous & $\mathrm{I} .6(3.1)$ & $0.14,0.07$ \\
depressive episodes & & \\
Number of previous & $0.2(\mathrm{I} .0)$ & $0.24,0.15$ \\
mixed episodes & & \\
YMRS score & $3.8(5.7)$ & $0.15,<0.0 \mathrm{I}$ \\
MADRS score & $4.9(6.6)$ & $0.30,<0.0 \mathrm{I}$ \\
CGI-BP-S mania score & $\mathrm{I} .7(\mathrm{I} .2)$ & $0.17,<0.0 \mathrm{I}$ \\
CGI-BP-S depression score & $\mathrm{I} .5(\mathrm{I} .0)$ & $0.27,<0.0 \mathrm{I}$ \\
CGI-BP-S overall score & $\mathrm{I} .8(\mathrm{I} .2)$ & $0.23,<0.0 \mathrm{I}$ \\
\hline
\end{tabular}

Abbreviations: CGI-BP-S, Clinical Global Impression Severity of Illness Scale for Bipolar Disorder; MADRS, Montgomery Asberg Depression Rating Scale; SD, standard deviation; YMRS, Young Mania Rating Scale. 
Table 2 Sociodemographic/clinical characteristics and suicide risk in Thai bipolar I disorder patients

\begin{tabular}{|c|c|c|c|}
\hline $\begin{array}{l}\text { Sociodemographic/clinical } \\
\text { characteristics }\end{array}$ & $\begin{array}{l}N=383 \\
n(\%)\end{array}$ & $\begin{array}{l}\text { Mean } \\
(\mathrm{SD})\end{array}$ & $\begin{array}{l}\text { Significant } \\
\text { difference }^{\mathrm{a}}\end{array}$ \\
\hline Sex & & & $t=-|.5|$ \\
\hline Male & $150(39.2)$ & $\mathrm{I} .4(3.2)$ & $P=0.09$ \\
\hline Female & $233(60.8)$ & $2.2(5.8)$ & \\
\hline Marital status & & & $F=1.21$, \\
\hline Single & $132(34.5)$ & $1.5(3.6)$ & $P=0.30$ \\
\hline Married & $192(50.1)$ & $2.3(6.2)$ & \\
\hline Divorced/widowed & $59(15.4)$ & $1.5(3.0)$ & \\
\hline A history of hospitalization ${ }^{\mathrm{b}}$ & & & $F=0.58$, \\
\hline Yes & $231(60.3)$ & $1.9(4.5)$ & $P=0.56$ \\
\hline No & $124(32.4)$ & $1.6(5.3)$ & \\
\hline Type of first mood episode & & & $F=4.95$, \\
\hline Depression & $92(24.0)$ & $2.9(6.1)$ & $P<0.01$ \\
\hline Mania/hypomania & $252(65.8)$ & $1.3(3.4)$ & \\
\hline Mixed & $27(7.0)$ & $4.4(19.3)$ & \\
\hline Undetermined & $12(3.1)$ & $0.7(1.6)$ & \\
\hline A history of rapid cycling ${ }^{b}$ & & & $t=6.94$ \\
\hline Yes & $30(8.1)$ & $11.0(19.1)$ & $P<0.0$ I \\
\hline No & 342 (91.9) & I.8 (4.7) & \\
\hline Anxiety disorders (panic, & & & $t=-2.45$ \\
\hline agoraphobic, social anxiety, & & & $P=0.02$ \\
\hline \multicolumn{4}{|l|}{ OCD, PTSD, or GAD) } \\
\hline Yes & $48(12.5)$ & $4.9(9.6)$ & \\
\hline No & $335(87.4)$ & $1.5(3.8)$ & \\
\hline Alcohol use disorders (alcohol & & & $t=-0.68$ \\
\hline dependence + alcohol abuse) & & & $P=0.01$ \\
\hline Yes & $30(7.8)$ & $1.61(4.7)$ & \\
\hline No & $353(92.2)$ & $1.6(4.7)$ & \\
\hline Substance dependence/abuse & & & $t=-0.53$ \\
\hline Yes & $10(2.6)$ & $2.7(5.1)$ & $P=0.60$ \\
\hline No & $373(97.4)$ & $1.9(5.0)$ & \\
\hline Psychiatric disorder & & & $t=0.74$ \\
\hline in first-degree relatives & & & $P=0.46$ \\
\hline Yes & $117(30.5)$ & $2.2(6.0)$ & \\
\hline No & $266(69.4)$ & $1.8(4.5)$ & \\
\hline
\end{tabular}

Notes: 'Student's $t$-test for between group difference and one-way analysis of variance for among group difference; bhistory of hospitalization in 22 patients and history of rapid cycling in eleven patients were undetermined due to missing data. Abbreviations: GAD, generalized anxiety disorder; OCD, obsessive-compulsive disorder; PTSD, post-traumatic stress disorder; SD, standard deviation.

current anxiety disorders $(P=0.02)$, and current alcohol use disorders $(P<0.01)$ (Table 2$)$.

The stepwise multiple linear regression model revealed that the MADRS score $(\beta=0.10)$, a history of rapid cycling $(\beta=6.63)$, current anxiety disorders $(\beta=2.16)$, and current alcohol use disorders $(\beta=2.65)$ were significantly correlated with the suicide risk score (all $P<0.01$ ) (Table 3 ). The model predicted $21 \%$ of the suicide risk score $\left(R^{2}=0.22\right.$; adjusted $\left.R^{2}=0.21 ; F=26.17, P<0.01\right)$.

\section{Discussion}

This prospective study of Thai BD I patients was dominated by outpatients. The low YMRS, MADRS, and MINI
Table 3 Stepwise multiple linear regression of factors predicting the suicide risk (to enter: $P=0.1$; to leave: $P=0.2$ )

\begin{tabular}{|c|c|c|c|c|c|c|}
\hline \multirow[t]{2}{*}{ Risk factor } & \multirow[t]{2}{*}{$\beta$} & \multirow[t]{2}{*}{ SE $(\beta)$} & \multirow[t]{2}{*}{$t$} & \multirow[t]{2}{*}{$P$} & \multicolumn{2}{|c|}{$\begin{array}{l}95 \% \text { confidence } \\
\text { interval }\end{array}$} \\
\hline & & & & & $\begin{array}{l}\text { Lower } \\
\text { bound }\end{array}$ & $\begin{array}{l}\text { Upper } \\
\text { bound }\end{array}$ \\
\hline Constant* & 13.78 & 2.06 & 6.68 & $<0.01$ & 9.73 & 17.84 \\
\hline $\begin{array}{l}\text { A history of } \\
\text { rapid cycling }\end{array}$ & 6.63 & 1.02 & 6.48 & $<0.01$ & 8.65 & 4.62 \\
\hline MADRS & 0.10 & 0.04 & 2.72 & $<0.01$ & 0.03 & 0.18 \\
\hline $\begin{array}{l}\text { Anxiety } \\
\text { disorders }\end{array}$ & 2.16 & 0.73 & 2.97 & $<0.01$ & 0.73 & 3.58 \\
\hline $\begin{array}{l}\text { Alcohol use } \\
\text { disorders }\end{array}$ & 2.65 & 0.85 & 3.11 & $<0.01$ & 0.97 & 4.33 \\
\hline
\end{tabular}

Notes: $* R^{2}=0.22$, adjusted $R^{2}=0.21, F=26.17, P<0.01$.

Abbreviations: MADRS, Montgomery Asberg Depression Rating Scale; SE, standard error.

suicidality scores suggested that these participants were mildly ill. However, this study still found that a history of rapid cycling, the severity of depressive state, current anxiety disorders, and current alcohol use disorders are the statedependent risk factors of suicide in this population. Although these four factors correlated well with current suicidality, the low adjusted $R^{2}$ of 0.21 suggests that many factors not included in this study also played a role, eg, family history of suicide or mood disorders, early negative life events, psychosocial stressors, serious medical illness, lack of social or family support, psychotic symptoms, atypical features.

The association between current suicide risk and rapid cycling found in this study is consistent with previous findings. In a meta-analysis, rapid cycling increased the odds of attempted suicide for 1.54-fold in BD patients. ${ }^{7}$ However, a recent study found that rapid cycling increased only lifetime suicidal ideation but not lifetime suicide attempts. ${ }^{25}$

The present findings confirm the association of depression severity and suicide risk. Suicidal behavior is a part of major depression and all measures used for assessing depression severity. Almost $80 \%$ of BD suicides occur during a major depressive episode. ${ }^{26}$ In an 18-month follow-up study, depressive phase at index episode was a predictor of suicide attempts. ${ }^{27}$ Even mixed mania, a manic episode with limited symptoms of depression, the chance of suicidal behavior also increases 26.7-fold compared with pure mania. ${ }^{28}$

Anxiety disorders are a noteworthy risk factor for suicide in BD patients. Although the lifetime prevalence of these disorders might be as high as $86.7 \%,{ }^{29}$ the prevalence was only $26.7 \%$ in Taiwanese patients with BD. ${ }^{30}$ The low prevalence of current anxiety disorders in the present cohort (12.5\%) might be caused by the use of MINI, which mainly detected current mental disorders, or by nature of the low prevalence 
of anxiety disorders in Asian BD patients. However, these findings still replicated the meta-analytic results and suggest that comorbid anxiety disorder increased the risk of suicide attempts in BD I patients. ${ }^{7}$

Alcohol abuse and dependence may be found in $38.0 \%-56.3 \%$ of BD I individuals. ${ }^{29}$ The results of this study suggest that alcohol use disorders in the past year increase the current risk of suicidality in BD I patients. These findings are in line with the results of a meta-analysis and a recent study in Europe, which found that alcohol use disorders increased lifetime suicide attempts. ${ }^{7,31}$ As lifetime alcohol use disorders may be found in $42.6 \%$ of BD patients, ${ }^{32}$ this common comorbidity may play an important role in increasing the suicidality in BD patients.

Several risk factors shown in previous studies were not found in the present one (eg, early onset of illness, ${ }^{33,34}$ duration of untreated illness, ${ }^{35}$ substance abuse comorbidity $^{36,37}$ ). The present mean age of onset (31.3 years) was later than those of previous findings (18-24 years). ${ }^{38}$ The mean duration of untreated illness (4.2 years) was also shorter than Western findings (eg, 9.6 years in France). ${ }^{39}$ As ethnicity did not have a significant influence on the age of onset, ${ }^{40}$ these findings might reflect the unawareness of mild mood disturbance in the early stage of BD. The fact that the substance abuse module of MINI focuses only on the previous year might be a cause of the low prevalence of substance abuse comorbidity.

The present study design and sample were relatively different from those of previous studies, and these issues should be taken into account when interpreting the results of this study. While the key outcomes of most studies were suicides and lifetime suicide attempts, the present one intended to examine the current or the state-dependent suicide risk, taking into account all current suicidal behaviors and a history of attempted suicide. The present findings therefore reflect the more current problem of suicidality. The prevalence of attempted suicide, which was the most common suicidal behavior in this study, was only $20.6 \%$ compared with that of European studies $(21 \%-54 \%){ }^{6}$ It is possible that the differences in study design and subjects (mainly Thai outpatients) play an important role in causing the dissimilarities in results.

There were some limitations in this study. First, the sample size of 383 is relatively small for a multivariate study. False negative findings for some risk factors could therefore not be ruled out. Second, this study had multiple testing, which might lead to the problem of false positive findings. However, the high significance $(P<0.01)$ for all four factors may indicate less cause for concern in regard to this problem. Third, the characteristics of this sample were unique. They were Thai BD I patients, who currently had mild mood symptoms and low suicidality. The present findings may not be able to generalized to BD I patients with severe mood episodes. Last, some variables (eg, age at onset, number of previous episodes) were based on patients' subjective perception, and therefore include a recall bias.

The present results provide another perspective of suicide risks among BD I patients. While most of the previous studies mainly focused on a long-term course of complete suicide or suicide attempts, the present one adds the evidence of the current clinical features affecting current suicide risk. In addition, these results confirm that some predictors of long-term suicidal behavior, eg, depression, a history of rapid cycling, comorbidity of anxiety/alcohol use disorders, are also correlates with current suicide risk.

\section{Conclusion}

A history of rapid cycling, severity of depressive episode, current anxiety disorders, and current alcohol use disorders correlate with current suicide risk among Thai BD I patients. The presence of these clinical features should raise the physician's awareness on the currently high suicidality in these patients. Further studies in larger sample sizes are warranted.

\section{Acknowledgments}

This study was supported by an unrestricted research grant from Sanofi (Thailand) Ltd. However, Sanofi-Aventis (Thailand) had no role in the study design, analysis plan, and preparation of this manuscript. Statistical analysis was provided by Dr Jaruek Charoensap and Ms Taweeporn Natesamroeng, statisticians of Sanofi (Thailand) Ltd. The authors thank Dr Panadda Klamsum of Sanofi (Thailand) Ltd for her administrative support.

The findings are presented here on behalf of the Thai Bipolar Registry Group: R Kanokvut, P Lengdee, U Wilekha, Buddhachinnaraj Hospital; W Pratoomsri, Chachoengsao Hospital; W Thomkapanich, Galya Rajanagarindra Institute; P Onsiri, Institute of Aviation Medicine; K Kittiwattanagul, Khon Kaen Rajanagarindra Psychiatric Hospital; P Lueboonthavatchai, C Roomruangwong, S Tangwongchai, King Chulalongkorn Memorial Hospital; M Srisurapanont, S Suttajit, Maharaj Nakorn Chiang Mai Hospital; S Tongprasert, Phrae Hospital; T Leelahanaj, P Chongrak, Phramongkutklao Hospital; S Sarakul, Phrapokklao Hospital; S Janthong, T Kongsuk, Prasrimahabhodhi Psychiatric Hospital; 
P Thomyangkoon, Rajavithi Hospital; P Ittasakul, R Kongsakon, Ramathibodi Hospital; S Limsiroratana, W Pattanakumjorn, Ratchaburi Hospital; P Pattaranuthaporn, Rayong Hospital; S Bussaratid, Siriraj Hospital; W Chanakul, P Losatiankij, Somdet Chaopraya Institute of Psychiatry; S Paholpak, Srinagarind Hospital; S Choovanichvong, Srithanya Hospital; S Joowong, Suansaranrom Psychiatric Hospital; K Surapongpiwattana, T Surapongpiwattana, Surin Hospital; L Kosulwit, Thammasat University Hospital; W Wongsuriyadech, Udonthani Hospital; T Sumpatanarax, Vachira Phuket Hospital.

\section{Disclosure}

The following authors have received consultancy fees, research grants, and/or honoraria from industry but none related to this work: Sirijit Suttajit from AstraZeneca and Janssen; Suchat Paholpak from AstraZeneca, Janssen, Novartis, Pfizer, Sanofi-Aventis, and Thai Otsuka; Manit Srisurapanont from AstraZeneca, GlaxoSmithKline, Pfizer, Janssen, Johnson and Johnson, Lundbeck, SanofiAventis, Servier, and Thai Otsuka. Somrak Choovanicvong, Khanogwan Kittiwattanagul, and Wetid Pratoomsri report no conflicts of interest in this work.

\section{References}

1. Muller-Oerlinghausen B, Berghofer A, Bauer M. Bipolar disorder. Lancet. 2002;359(9302):241-247.

2. Dutta R, Boydell J, Kennedy N, J Van Os J, Fearon P, Murray RM. Suicide and other causes of mortality in bipolar disorder: a longitudinal study. Psychol Med. 2007;37(6):839-847.

3. Chen YW, Dilsaver SC. Lifetime rates of suicide attempts among subjects with bipolar and unipolar disorders relative to subjects with other Axis I disoders. Biol Psychiatry. 1996;39(10):896-899.

4. Kessler RC, Borges G, Walters EE. Prevalence of and risk factors for lifetime suicide attempts in the National Comorbidity Survey. Arch Gen Psychiatry. 1999;56(7):617-626.

5. Harris E, Barraclough B. Suicide as an outcome for mental disorders: a meta-analysis. Br J Psychiatry. 1997;170:205-228.

6. Fajutrao L, Locklear J, Priaulx J, Heyes A. A systematic review of the evidence of the burden of bipolar disorder in Europe. Clin Pract Epidemiol Ment Health. 2009;5:3.

7. Hawton K, Sutton L, Haw C, Sinclair J, Harriss L. Suicide and attempted suicide in bipolar disorder: a systematic review of risk factors. J Clin Psychiatry. 2005;66(6):693-704.

8. Dunner DL. Correlates of suicidal behavior and lithium treatment in bipolar disorder. J Clin Psychiatry. 2004;65(Suppl 10):5-10.

9. Gonda X, Pompili M, Serafini G, et al. Suicidal behavior in bipolar disorder: epidemiology, characteristics and major risk factors. $J$ Affect Disord. 2012;143(1-3):16-26.

10. Osman A, Bagge CL, Gutierrez PM, Konick LC, Kopper BA, Barrios FX. The Suicidal Behaviors Questionnaire-Revised (SBQ-R): validation with clinical and nonclinical samples. Assessment. 2001;8(4):443-454.

11. Kuo WH, Gallo JJ, Tien AY. Incidence of suicide ideation and attempts in adults: the 13-year follow-up of a community sample in Baltimore, Maryland. Psychol Med. 2001;31(7):1181-1191.
12. Bhui KS, Dinos S, McKenzie K. Ethnicity and its influence on suicide rates and risk. Ethn Health. 2012;17(1-2):141-148.

13. Chen YY, Wu KC, Yousuf S, Yip PS. Suicide in Asia: opportunities and challenges. Epidemiol Rev. 2012;34(1):129-144.

14. Tsai SY, Lee JC, Chen CC. Characteristics and psychosocial problems of patients with bipolar disorder at high risk for suicide attempt. J Affect Disord. 1999;52(1-3):145-152.

15. Rihmer Z. Suicide risk in mood disorders. Curr Opin Psychiatry. 2007;20(1):17-22.

16. Leelahanaj T, Kongsakon R, Choovanichvong S, et al. Time to relapse and remission of bipolar disorder: findings from a 1-year prospective study in Thailand. Neuropsychiatr Dis Treat. 2013;9:1249-1256.

17. Sheehan DV, Lecrubier Y, Sheehan KH, et al. The Mini-International Neuropsychiatric Interview (MINI): the development and validation of a structured diagnostic psychiatric interview for DSM-IV and ICD-10. J Clin Psychiatry. 1998;59(Suppl 20):22-33.

18. Young RC, Biggs JT, Ziegler VE, Meyer DA. A rating scale for mania: reliability, validity and sensitivity. Br J Psychiatry. 1978;133: 429-435.

19. Montgomery SA, Asberg M. A new depression scale designed to be sensitive to change. Br J Psychiatry. 1979;134:382-389.

20. Spearing MK, Post RM, Leverich GS, Brandt D, Nolen W. Modification of the Clinical Global Impressions (CGI) Scale for use in bipolar illness (BP): the CGI-BP. Psychiatry Res. 1997;73(3):159-171.

21. Ware JE Jr, Sherbourne C. The MOS 36-Item Short-Form Health Survey (SF-36). I. Conceptual framework and item selection. Med Care. 1992;30:473-483.

22. Ware JE, Snow KK, Kosinski M, Gandek B. SF-36 Health Survey: Manual and Interpretation Guide. Boston, MA: The Health Institute; 1993.

23. Truant GS, O'Reilly R, Donaldson L. How psychiatrists weigh risk factors when assessing suicide risk. Suicide Life Threat Behav. 1991;21(2):106-114.

24. Novick DM, Swartz HA, Frank E. Suicide attempts in bipolar I and bipolar II disorder: a review and meta-analysis of the evidence. Bipolar Disord. 2010;12(1):1-9.

25. Garcia-Amador M, Colom F, Valenti M, Horga G, Vieta E. Suicide risk in rapid cycling bipolar patients. J Affect Disord. 2009;117(1-2):74-78.

26. Isometsa ET, Henriksson MM, Aro HM, Lonnqvist JK. Suicide in bipolar disorder in Finland. Am J Psychiatry. 1994;151(7):1020-1024.

27. Valtonen HM, Suominen K, Mantere O, Leppamaki S, Arvilommi P, Isometsa ET. Prospective study of risk factors for attempted suicide among patients with bipolar disorder. Bipolar Disord. 2006;8(5 Pt 2): 576-585.

28. Dilsaver SC, Chen YW, Swann AC, Shoaib AM, Krajewski KJ. Suicidality in patients with pure and depressive mania. Am JPsychiatry. 1994;151(9):1312-1315.

29. Merikangas KR, Akiskal HS, Angst J, et al. Lifetime and 12-month prevalence of bipolar spectrum disorder in the National Comorbidity Survey replication. Arch Gen Psychiatry. 2007;64(5):543-552.

30. Chang YH, Chen SL, Chen SH, et al. Low anxiety disorder comorbidity rate in bipolar disorders in Han Chinese in Taiwan. Prog Neuropsychopharmacol Biol Psychiatry. 2012;36(1):194-197.

31. Bellivier F, Yon L, Luquiens A, et al. Suicidal attempts in bipolar disorder: results from an observational study (EMBLEM). Bipolar Disord. 2011;13(4):377-386.

32. Regier DA, Farmer ME, Rae DS, et al. Comorbidity of mental disorders with alcohol and other drug abuse. Results from the Epidemiologic Catchment Area (ECA) Study. JAMA. 1990;264(19):2511-2518.

33. Perlis RH, Miyahara S, Marangell LB, et al. Long-term implications of early onset in bipolar disorder: data from the first 1000 participants in the systematic treatment enhancement program for bipolar disorder (STEP-BD). Biol Psychiatry. 2004;55(9):875-881.

34. Leverich GS, Altshuler LL, Frye MA, et al. Factors associated with suicide attempts in 648 patients with bipolar disorder in the Stanley Foundation Bipolar Network. J Clin Psychiatry. 2003;64(5):506-515. 
35. Altamura AC, Dell'Osso B, Berlin HA, Buoli M, Bassetti R, Mundo E. Duration of untreated illness and suicide in bipolar disorder: a naturalistic study. Eur Arch Psychiatry Clin Neurosci. 2010;260(5):385-391.

36. Oquendo MA, Mann JJ. Identifying and managing suicide risk in bipolar patients. J Clin Psychiatry. 2001;62(Suppl 25):31-34.

37. Lopez P, Mosquera F, de Leon J, et al. Suicide attempts in bipolar patients. J Clin Psychiatry. 2001;62(12):963-966.
38. Bauer M, Glenn T, Alda M, et al. Impact of sunlight on the age of onset of bipolar disorder. Bipolar Disord. 2012;14(6):654-663.

39. Drancourt N, Etain B, Lajnef M, et al. Duration of untreated bipolar disorder: missed opportunities on the long road to optimal treatment. Acta Psychiatr Scand. 2013;127(2):136-144.

40. Javaid N, Kennedy JL, De Luca V. Ethnicity and age at onset in bipolar spectrum disorders. CNS Spectr. 2011;16(6):127-134.

\section{Publish your work in this journal}

Neuropsychiatric Disease and Treatment is an international, peerreviewed journal of clinical therapeutics and pharmacology focusing on concise rapid reporting of clinical or pre-clinical studies on a range of neuropsychiatric and neurological disorders. This journa is indexed on PubMed Central, the 'PsycINFO' database and CAS.
The manuscript management system is completely online and includes a very quick and fair peer-review system, which is all easy to use. Visit http://www.dovepress.com/testimonials.php to read real quotes from published authors.

Submit your manuscript here: http://www.dovepress.com/neuropsychiatric-disease-and-treatment-journal 